\title{
Táticas operárias de defesa de si: controle da produção fabril, do corpo e dos valores ${ }^{1}$
}

\author{
Cristiane A. Fernandes da Silva ${ }^{2}$ \\ Universidade Federal de Uberlândia (Uberlândia, MG)
}

As relações estabelecidas pelos operários e os modos com que constroem o cotidiano fabril revelam táticas de autodefesa, tanto no que se refere ao seu corpo quanto aos seus valores culturais. Analisar essas táticas, apresentando algumas formas concretas de sua realização, consiste no objetivo focal deste artigo. A abordagem empregada aqui é qualitativa, concretizada pelo método rede social, sendo as entrevistas individuais e semidiretivas a principal técnica utilizada para apreender as interpretações de operários de metalúrgicas do $\mathrm{ABC}$, região metropolitana de São Paulo. Sua análise é constituída tanto pelos achados revelados pelos sujeitos de pesquisa entrevistados quanto por autores de diferentes áreas do conhecimento, imprimindo, portanto, uma perspectiva pluridisciplinar. Os resultados desta pesquisa revelam: o controle da produção, pelo operário, a partir do ritmo do seu corpo; a elaboração de estratégia contra a intensificação do trabalho; a existência de conflitos entre os seus limites corporais e os seus valores culturais e a introdução de marcas pessoais na construção de objetos-massa. Por meio desses resultados, conclui-se que o operário não se porta passiva e mecanicamente em seu trabalho, mas demonstra, em grande medida, posturas ativas de sujeitos interventores em seu cotidiano na fábrica, ainda que se restrinja a instâncias mais intimistas, portanto, agindo astuciosamente.

Palavras-chave: Trabalho, Operário, Sujeito, Valores, Corpo.

Workers' tactics of self-defense: manufacturing control of production, body and values

The relations established by the workers and the ways in which they build the everyday factory reveal self-defense tactics, both with regard to his body as to their cultural values. Analyze these tactics, showing some concrete ways of its realization, is the focal objective of this article. The approach employed here is qualitative, particularly through social network method, being the individual interviews and semi-directive the main technique used to collect the interpretations of workers from metallurgical in $\mathrm{ABC}$, metropolitan region of São Paulo. The analysis is formed both by the reported thinks from subject of search interviewed, as by authors from different areas of knowledge, printing, therefore, a multidisciplinary approach. The survey results reveal the control of production, by worker, from the rhythm of his body, its elaboration of strategy against the intensification of work, the existence of conflicts between their bodily limits and his cultural values and the introduction of personal brands in construction of mass objects. From these results, it is concluded that the worker does not behave passive and mechanical in his work, but he demonstrates an active behave of subject intervening in his everyday lives in the factory, even if more restricted to intimate instances, therefore, acting artfully.

Keywords: Labor, Worker, Subject, Values, Body.

\section{Introdução}

A s práticas dos operários de chão de fábrica são elaboradas a partir de densos sentidos culturais, cuja diversidade e crítica passam ao largo da análise que lhes confere significados atinentes somente à homogeneização, à massificação e à alienação.

O objetivo central deste artigo consiste em mostrar que o cotidiano fabril é construído a partir de táticas operárias de autodefesa, concretizadas pelas mais variadas e

1 Este artigo deriva de parte do quinto capítulo da tese de doutorado da autora, intitulada A gestão de si na reinvenção das normas: práticas e subjetividade no trabalho, defendida em 2007, no departamento de Sociologia da Universidade de São Paulo, com o apoio do CNPq e da CAPES.

2 Professora adjunta de Sociologia da Universidade Federal de Uberlândia. 
inusitadas formas de readequação do espaço fabril aos limites e escolhas possíveis do seu corpo e/ou de seus valores. Nesses termos, os operários têm a meta produtiva apenas como um dos seus alvos a serem atingidos no trabalho, pois eles balizam a produção fabril a partir da busca da garantia de suas próprias necessidades físicas e simbólicas.

Para apreender os sentidos dessas práticas, elaboradas pelos próprios operários, é preciso dispor de recurso metodológico que valorize efetivamente o olhar dos sujeitos de pesquisa, tomando-os não como meros depoentes, mas como sujeitos ativos e interventores de sua micro-história cotidiana.

Com o intuito de acessar as experiências dos sujeitos analisados, este artigo se debruça sobre as falas de operários com os quais estabelecemos contatos por meio do método rede social, montado a partir de indicações de conhecidos. Sua definição consiste em um "conjunto de relações que ligam pessoas, posições sociais [...], grupos e organizações" (Johnson, 1997, p. 190) ${ }^{3}$. Por termos recorrido a agentes e não a agências de contatos, esse tipo de método imprime sentido informal na relação pesquisadora-pesquisado, favorecendo o afastamento de eventuais constrangimentos advindos das relações institucionais.

Na perspectiva de Bourdieu, investigar pessoas conhecidas "garante" uma comunicação "não violenta" devida à não objetivação das razões subjetivas do pesquisado e da imediata compreensão dos seus sinais não verbais (1987, p. 697). Destarte, existe a necessidade da escolha de um método de pesquisa que favoreça o contato direto e uma relação mais informal com os pesquisados do que aquela que se instaura dentro de uma fábrica. Portanto, foi tentando se aproximar desse propósito que o método rede social foi incorporado nesta pesquisa.

As experiências narradas são sempre aquelas que o sujeito que as vivenciou considera significativas. Schutz sublinha que o significado desse tipo de experiência é predicado, pretérito, retrospectivo, acabado, jamais se trata de um acontecendo, nunca está no gerúndio (1979, p. 63, p. 67). Sobressai aí a importância da memória para o relato das experiências dos sujeitos sociais, que implica o reconstruir de suas vivências, de acordo com os significados que o próprio narrador lhes atribui e dispõe no presente.

Nesse sentido, a metodologia ora empregada é qualitativa, constituída por entrevistas ${ }^{4}$ individuais e semidiretivas, conduzidas por intermédio de formulários de questões estruturadas por eixos temáticos e cronológicos. Todas as entrevistas foram gravadas e realizadas nas residências dos operários com o intuito de conhecê-los o mais próximo possível do seu ambiente familiar.

Os sujeitos desta pesquisa totalizam 21, montante alcançado quando se julgou já ter acessado experiências suficientemente diversas do ponto de vista qualitativo cuja abrangência permitia atingir o escopo da pesquisa. São todos metalúrgicos de montadoras do ABC, Grande São Paulo. Seus perfis são variados em faixas etárias, sexos, funções e tempos de serviço, o que possibilita maior pluralidade de informações nos relatos de suas diferentes experiências. A escolha desses operários foi aleatória, tendo como filtro apenas o perfil de metalúrgicos de chão de fábrica de montadoras do $\mathrm{ABC}$; recorte favorecido pelo método rede social que prima por contatos voltados para o perfil pretendido. $\mathrm{O}$ início dessa rede foi composto por um operário que já havia participado de nossa pesquisa de mestrado. Vale sublinhar que os nomes desses operários são fictícios, uma forma empregada para preservar a sua identidade.

\footnotetext{
3 Mais detalhes sobre o método rede social, ver a obra da antropóloga Both (1976), uma de suas precursoras na Inglaterra.

4 Para Thiollent (1982), entrevistas, questionários e formulários são "técnicas de observação direta pelo fato de permitirem um contato efetivo com as pessoas implicadas no problema investigado” (p. 32).

5 Conferir em Thiollent (1982) duas outras formas de estruturar um questionário: correspondente às hipóteses e arbitrária.
} 
Concomitantemente à exposição e análise de suas falas é apresentada uma perspectiva pluridisciplinar de psicólogos, sociólogos, historiadores e ergólogos ${ }^{6}$, como: Oddone, Re e Briante, Clot, Dejours, Sato, Carvalho, Bernoux, Fischer, Durand, Rosa, Certeau e Schwartz. Portanto, para conferir uma dinâmica mais voltada para os resultados desta pesquisa, optou-se por apresentá-los intercalados à discussão teórica, ao invés de trazer esta separadamente no início do artigo.

Visando circunscrever as práticas operárias, foram selecionados aqui quatro gêneros delas: controle da produção a partir do ritmo do corpo, elaboração de estratégia contra a intensificação do trabalho, conflitos entre limites corporais e valores simbólicos e, finalmente, a impressão pessoal na construção de objetos-massa.

\section{Astúcia operária e tempo do corpo}

Quando analisado microscopicamente, o cotidiano fabril revela inúmeras habilidades astuciosas empregadas pelos operários para gerirem suas atividades ${ }^{7}$. Esse agir astucioso concerne a uma prática que ultrapassa a contemporaneidade e o ambiente de trabalho, remontando os tempos longínquos de nossa civilização.

Conta-nos a cosmologia da antiguidade clássica grega que a astúcia era uma virtude pertencente exclusivamente à deusa Mêtis, a primeira esposa de Zeus, rei dos deuses e dos homens. Segundo Vernant, estudioso da vida na Grécia, mêtis significa uma forma inteligente de conquistar o poder, sem jamais ser surpreendido e desorientado e "nunca abrir flanco para um ataque inesperado" (2003, p. 39). Temendo ser destronado por um filho seu, ainda no ventre de Mêtis, Zeus ironiza o poder que ela tem, de se metamorfosear em gota d'água; no momento em que ela demonstra essa habilidade, é engolida por ele. Assim, tendo em seu regaço Mêtis e sua filha Atenas, Zeus concentra dentro de si toda a astúcia do mundo, encarnando "no fluxo temporal, essa presciência ardilosa [a astúcia] que permite desfazer antecipadamente os planos de qualquer um que tente surpreendê-lo ou derrotá-lo" (Vernant, 2003, p. 40).

Muito embora seja Hefesto, filho de Zeus com Hera, o deus da metalurgia, dada sua excepcional habilidade artesã, é a virtude da deusa Mêtis que os operários metalúrgicos incorporam no interior da fábrica em suas táticas ardilosas. De forma análoga à atitude de Mêtis, esses operários também empregam astúcia visando conquistar certo poder, não o poder sobre o cosmo, mas sobre o seu próprio corpo - o controle dos seus possíveis e desejos.

À feição da astúcia grega, a astúcia operária busca antever as reações advindas de planos realizados externamente, sob cuja influência se encontram, elaborando artimanhas e providências com o intuito de impedir sua submissão a situações que desaprovem.

Ao analisar a inteligência astuciosa dos trabalhadores, Dejours (2004) pontua algumas características metapsicológicas, dentre as quais a do seu enraizamento no corpo do trabalhador. Segundo o autor: "Um barulho, uma vibração, um cheiro, um sinal visual podem chamar a atenção do sujeito, mas antes chama a atenção do corpo desse sujeito [...] Essa

\footnotetext{
6 Ergólogos são profissionais da ergologia, uma abordagem com o propósito de analisar o trabalho do ponto de vista daquele que trabalha. Para mais informações e bibliografia a respeito, consultar o site www.ergologie.fr.

7 A vertente francofônica da Ergonomia da Atividade faz uma distinção bastante precisa entre tarefa e atividade: o primeiro termo diz respeito aos "desempenhos exigidos na situação de trabalho" e aos "procedimentos prescritos" para a realização da tarefa; já o segundo termo se refere às atividades efetivamente realizadas pelos trabalhadores, caracterizadas essencialmente pelos "procedimentos utilizados" e pelas “condutas inteligentes" (Montmollin, 1986, p. 20). Trata-se de distinção bastante pertinente para esta pesquisa à medida que sustenta haver, por parte do operário, atuação tática e inteligente, e não de simples observância prescritiva com relação às normas oficiais.
} 
dimensão corpórea da inteligência [...] implica um funcionamento [...] diferenciado do raciocínio lógico" (pp. 281-289). Portanto, mais voltada para os valores e a subjetividade ${ }^{8}$ do sujeito.

Com o intuito de compreender essa inteligência corpórea, realizamos trabalho de campo que revelou o tempo como o protagonista da trama que envolve o trabalhador fabril. Os operários se esforçam por tentar controlá-lo, para gerir seu cotidiano de trabalho. Entrementes, uma vez que se constata a discordância existente entre "aqueles que organizam o tempo e aqueles que o gerem" (Oddone, Re \& Briante, 1981, p. 132), ${ }^{9}$ os operários têm de recorrer a estratagemas, desenvolvendo habilidades semelhantes às virtudes da deusa grega.

Essa habilidade operária vai ao encontro da noção de kairos, uma expressão grega, analisada por Schwartz (2000) que, ao citar Monique Trede, a define como "um certo tipo de inteligência [...] que permite à ação humana se exercer em circunstâncias indefinidamente variadas [...] exigindo do homem adaptações sempre novas e se opondo a todo sistema" (p. 457).

A plasticidade do indivíduo é crucial mesmo em ambientes de trabalho automatizados. Na pesquisa de Clot, Rochex e Schwartz (1990), um eloquente testemunho notabiliza o papel do operário em uma indústria automobilística: "O robô faz a solda [...] mas [...] nós estamos lá, digamos, para fazê-lo funcionar permanentemente. É preciso que a gente tenha o nariz em todo lugar" (p. 108). Ou seja, ainda que grande parte das funções dos antigos operários tenha sido automatizada e substituída pela robótica, sempre é necessário que haja gente para vigiá-la e garantir o seu pleno funcionamento, pois, no processo de produção, há dimensões inatingíveis pela lógica mecânica e algorítmica dos maquinários e dos sistemas informacionais.

Uma das astúcias empregadas pelos operários pesquisados, em seu ambiente de trabalho, no que tange ao tempo, consiste em adaptar, na medida do possível, o ritmo da produção à "pulsão" ${ }^{0}$ do seu próprio corpo. O analista de processos de produção e expreparador de carroceria, Alex, 22 anos, testemunha: "Minha preocupação sempre foi essa: que eu não me desgastasse muito [...] Então, comecei a usar do tempo do meu [...] organismo pra [...] [manter] o ritmo da produção, a batida da produção, pra conseguir ter o mínimo de problemas físicos".

Esse operário utiliza o seu tempo corporal para cumprir o ritmo da produção, e não o contrário; a produção não tem o controle total do seu corpo, que é quem, de fato, assume certo papel de maestro para reger a batida da produção. A produção marca o tempo, porém o tempo em si é do trabalhador; portanto, o tempo não é apropriado pela produção, mas é usado pelo trabalhador, que sempre busca respeitar seus limites pessoais.

Efetivamente, a astúcia de tentar reger o ritmo da produção pelo tempo subjetivo do operário concretiza-se pela antecipação da produção, deixando períodos vazios entre as etapas de trabalho, utilizados de acordo com suas necessidades físicas e subjetivas.

Em outra fala, Alex relata que, quando trabalhava como preparador de carroceria: "eu ficava teimando comigo: [...] 'eu não vou ficar burro [...] ignorante $[\ldots]$ alienado $[\ldots][\mathrm{O}]$

8 Sobre a noção de subjetividade, ver Chaui, que não a restringe à personalidade de um indivíduo, mas a considera atravessada pelos sentidos advindos das relações sociais (1997, p. 19).

9 A respeito da distância entre a temporalidade teórica e a temporalidade real na fábrica, ver Schwartz (2003, pp. 21-30) explicitando quatro características da atividade humana: distância entre o prescrito e o real, ressingularização de normas, corpo-si gerindo os "buracos" das normas e debates de normas. Ver ainda Rosa, que compartilhando da perspectiva de Schwartz, aborda o trabalho como locus de confronto entre duas temporalidades: a dos valores mercantis da produtividade e a dos valores simbólicos e subjetivos (Rosa, 2000, p. 6).

10 Classicamente, o conceito de "pulsão" é tomado conforme a perspectiva de Freud, porém, aqui ele está remetido à abordagem de Schwartz (2000, p. 607) que não o restringe às esferas físicas e psíquicas, mas incorpora a dos valores. 
trabalho repetitivo para mim me estressava [...] Então eu procurava adiantar meu serviço, sentava na minha cadeira e lia". Percebe-se, portanto, que o tempo do corpo, aludido por esse operário nos dois momentos, aglutina, simultaneamente, as dimensões psicofísica e cultural, pois evidencia sua persistência em preservar sua saúde e seus valores culturais de cultivo da leitura.

A postura desse operário atesta a atividade de renormalização ${ }^{11}$, que em si implica uma "'relação de saúde', de vida, no trabalho, em que as transgressões civis se exprimem 'quer como reações de defesa biológica, quer como reações de defesa social, e nos dois casos como reações de saúde"' (Canguilhem apud Rosa, 2005, p. 32). ${ }^{12}$

Todavia, vale sublinhar que há mais margem de manobra para o uso da estratégia de adiantamento do trabalho em prol da saúde em setores como a pré-montagem e a usinagem, sendo menos recorrente na linha de montagem, onde o tempo é objeto de maior controle externo.

Os operários da pré-montagem e da usinagem conseguem acumular operações montando ou produzindo objetos em número superior ao exigido para um dado momento, ou mesmo, depois, acelerar o trabalho para cumprir a meta de produção.

Pablo, 23 anos, operário da pré-montagem, não suporta trabalhar de acordo com o ritmo indicado nos pedidos oficiais para a montagem de câmbio. Seu lema é trabalhar adiantado para tentar assenhorear-se do tempo fabril, transformando-o em seu próprio tempo: "Acho que cada um acaba instituindo a maneira melhor pra trabalhar".

Ele adianta a produção não apenas se baseando em estimativas que derivam de sua experiência no dia a dia, isto é, da quantidade e modelos de câmbios normalmente produzidos, mas também faz prognósticos antecipando situações ocorridas em tempo real. Efetivamente esse procedimento consiste na visita do operário ao setor imediatamente anterior ao seu, onde vê quais modelos de câmbios estão a caminho do seu setor; assim, já vai adiantando a sua montagem.

A conduta de Pablo torna-se facilmente compreensível se comparamos sua atitude no trabalho com seu comportamento fora dele. Trata-se de um jovem superativo, cuja energia parece inesgotável. Não suportaria esperar por determinações superiores para só então começar a sua atividade. Para atenuar a ansiedade pelo futuro próximo, ele necessita do controle antecipado desse porvir. É assim que ele vive, é assim que trabalha. ${ }^{13}$

Trabalhar adiantado é fisicamente possível porque esse jovem operário atua sobre uma bancada fixa. Sendo ele que se movimenta sobre ela, dispõe de espaço para estabelecer quão rápida ou lentamente poderá montar uma peça, segundo as limitações impostas pela meta de produção e também as pessoais.

Em sua pesquisa na linha de usinagem de uma montadora, Bernoux (1979) observou a redivisão do tempo de trabalho praticada pelos operários, contrariando o regulamento. Enquanto este previa o fracionamento do trabalho hora a hora, eles o reconfiguravam sobrecarregando-se no primeiro terço da jornada, não fazendo pausa, produzindo o máximo possível; no segundo terço, o ritmo seguia normal e, no último, menos pessoas trabalhavam (p.

11 Renormalizar é o recentramento do indivíduo em torno de suas próprias normas, é redesenhar as normas impostas em função de suas normas práticas; portanto, implicando, de certa forma, em uma postura de sujeitos ativos que constroem o seu cotidiano (Schwartz, 2000, p. 294).

12 Com o mesmo enfoque de Rosa, porém não voltado para o trabalho fabril, e sim para a escola, Athayde e Brito apresentam pesquisa que aborda estratégias de afirmação da vida e da saúde $(2003,71)$.

13 A postura de antecipação do porvir remete à noção de "colonização do futuro" de Giddens (1994). O autor revela uma nova relação estabelecida pelos indivíduos com a dimensão temporal na modernidade, a de colonizar o futuro antecipando, cognitivamente, o que poderá ocorrer. 
77). Essa mesma redivisão foi constatada junto aos entrevistados nesta pesquisa: eles aumentam o ritmo de trabalho na primeira parte da jornada, deixando a última menos sobrecarregada, preparando seus corpos para, aos poucos, interromperem os movimentos de labuta.

Com vistas a manter o controle do tempo, os operários pesquisados aqui desenvolveram uma técnica para reduzir os deslocamentos durante sua jornada de trabalho. Trata-se da técnica da "bolsinha", extensamente praticada entre os operários de setores fabris nos quais são usadas peças leves, como parafusos e arruelas.

Inácio, 39 anos, montador de linha, avalia o trabalho do montador de carroceria como penoso em razão dos longos trajetos percorridos na busca dos suprimentos necessários, o que ocasiona muita dor nas costas. Ele afirma que é preciso ser "esperto" e buscar técnicas, como a da bolsinha, para andar o mínimo possível, muito embora a fábrica se contraponha a seu uso por considerar que o transporte pode riscar o carro.

Essa postura demonstra a autoria e inventividade do próprio trabalhador na criação de um objeto a tiracolo, cujo uso visa reduzir o cansaço causado pelas andanças dentro da fábrica em busca de suprimentos. No decorrer do dia e com o passar dos meses, são quilômetros que deixaram de ser percorridos, bem como foram poupadas várias curvaturas da coluna vertebral e articulações diversas para pegar os materiais depositados em caixas no chão.

O montante de "tempo livre" alcançado pela prática da técnica da "bolsinha" permite ao trabalhador usufruir de ocasiões e momentos ressignificados por ele, dedicando-se ao relaxamento, ou à convivência social ou, mesmo, à introspecção e à leitura, possibilitando pausas para amealhar forças para prosseguir a labuta. ${ }^{14}$

A multiplicação de soluções acerca da gestão do tempo fabril é propiciada, segundo Rosa, pela "pulsão de saber" dos operários que os leva à superação de dificuldades quando se dedicam às atividades de trabalho. Dessa maneira, o sujeito desafia as normas impostas pelos modelos de organização do trabalho, porém de forma silenciosa, embora "real" e plural por resultar do "pluralismo de valores e conhecimentos". Assim, ele modifica, "mesmo que [...] parcialmente, o modo de trabalhar prescrito" e cria novas normas (Rosa, 2005, p. 32).

Vale ressaltar que, na prática, as astúcias exercidas pelos operários colocam-se como um tipo de controle cujas formas não são reconhecidas pela organização do trabalho. Tal controle tem, antes, um sentido de micromanobras, facultando uma futura construção de valores e práticas, coletivas e individuais. Conforme Sato (1997), esse controle operário apresenta-se como uma subcultura dentro da organização do trabalho, atuando oficiosa e astutamente (p. 8), embora funcione como parte do motor da própria organização.

\section{"Espaço manhoso" na fábrica}

Certas práticas ardilosas realizadas pelos operários são caracterizadas por eles como "manha", uma tática utilizada para conquistarem os ambientes fabris por onde transitam, tanto os espaços físicos quanto os simbólicos.

A constituição desse "espaço manhoso", dotado de astúcias, frequentemente só é visível entre os operários (e por vezes nem mesmo entre eles), já que se aperfeiçoam em

14 Sobre o controle do tempo fabril por parte do operário, ver Oddone, Re e Briante (1981), que analisam as astúcias operárias como uma heurística de controle do tempo de descanso, ausente nas normas fabris, e como uma afronta à organização do trabalho (p. 183). 
habilidades ilusionistas, inclusive revelando no próprio corpo marcas da verdade que querem mostrar especialmente para o engenheiro.

Um exemplo ilustrativo dessas habilidades é apresentado por Durand (1990): no momento em que um operário estava sendo cronometrado em seu tempo de trabalho, empenhou-se em tal complexidade de movimentos, normalmente desnecessária, simulando grande esforço e produzindo suor sobre o corpo. A oposição operária à cronometragem de seu trabalho fica patente nos escritos desse autor: "A arte de se fazer cronometrar consiste em dificultar, mas dando a impressão de trabalhar rápido [...] Nós encadeamos tantos gestos complicados e lentos para uma operação que na verdade só mereceria um gesto rápido e vivo" (Durand, 1990, pp. 99-100).

Nesta pesquisa, o engenheiro foi apontado por alguns operários que entrevistamos como a "figura do mal", cuja função consiste em lesar o operário, cronometrando seu tempo de trabalho e inventando técnicas e ferramentas para reduzir cada vez mais a necessidade do operário dentro da fábrica; portanto, destruindo suas possibilidades de trabalho.

A despeito do poder da engenharia de estabelecer normas sobre o tempo dos operários, no desenvolvimento de suas atividades estes gestam outro espaço dentro desse espaço coercitivo e obedecem a suas próprias normas. Certeau (2004) analisa a constituição desse espaço, nas "maneiras de fazer", por via de ações estilizadas: o indivíduo "cria para si um espaço de jogo para maneiras de utilizar a ordem imposta do lugar [...] Sem sair do lugar onde tem que viver e que lhe impõe uma lei, ele aí instaura pluralidade e criatividade [...] uma arte antiga de 'fazer com'” (pp. 92-93).

Os operários mais experientes e conscientes de que é preciso tomar certas precauções para não serem completamente dominados pelo tempo da produção constroem o que eles chamam de "espaço manhoso". Esse espaço consiste no controle e no uso que o trabalhador faz do seu tempo de trabalho quando está sendo cronometrado, notadamente disponibilizando para ser cronometrado um trabalhador considerado manhoso/esperto/ardiloso ou um cuja produção é média.

Concretamente, esse espaço manhoso, buscado para manter o controle sobre a matemática da racionalização do tempo de produção, efetiva-se por meio das técnicas de avançar ou retardar o ritmo dos movimentos, seja da máquina, medida em RPM (Rotação por Minuto), seja do próprio corpo do operário.

Avaliando a relação de seu trabalho com o tempo, um dos operários da Fiat de Turim, pesquisados por Oddone, Re e Briante $(1981)^{15}$, exprime-a com certo brio ao se autodeclarar um bom operário por conseguir tempo sobre aquele imposto pela fábrica. Seu método empregado, basicamente, consiste em sustentar o seu peso no pé esquerdo enquanto apoia o pé direito no pedal da prensa (o inverso do que os outros fazem), o que lhe faculta maior destreza de movimentos para retirar a mão da grade pouco antes de ela se fechar (pp. 65-66).

Vinculado ao método de trabalho criado por esse operário, existe na mesma proporção o risco. Ele emprega movimentos precisos, jamais aconselhados a um operário leigo; para ele, no entanto, trata-se somente de uma mecânica harmonizada e incorporada pelos movimentos sincrônicos do seu corpo. Há riscos, mas são controlados pela larga experiência do operário, pelo menos, aparentemente, enquanto não haja alguma falha advinda do próprio maquinário.

15 A metodologia empregada por Oddone, Re e Briante (1981) é de histórias individuais por sósias, narradas pelos delegados operários. Cada um destes dirigia-se a um seu suposto sósia (um professor) a quem o delegado era incumbido de fornecer instruções sobre o seu comportamento no trabalho. Trata-se de um recurso para fazer o próprio operário formalizar sua experiência informal, tornando-a transmissível, assim produzindo subsídio para que a psicologia do trabalho ultrapasse uma abordagem puramente analítica (p. 58). 
Para quem olha de fora certos atos arriscados dos operários, a primeira impressão é de imprudência; todavia, é preciso levar em conta que são ações repetidas infinitas vezes que permitem ao corpo, pela prática, alcançar movimentos hábeis e vigilantes.

Em Dassault-Mérignac, na França, um metalúrgico expôs para Schwartz uma solução astuciosa que emprega para controlar o tempo, intervindo nesse poder concedido oficialmente somente ao cronometrista. A técnica, também verificada entre os operários que entrevistamos, consiste em sobrepor várias peças para serem furadas simultaneamente, com isso ganhando tempo, pois, se fosse seguido o prescrito, apenas uma delas deveria ser furada por vez. Entretanto, essa astúcia só é empregada na ausência do cronometrista; diante dele, é seguido o prescrito; portanto, "sempre há escolhas a fazer" (Schwartz, 1988, p. 481). Tal atitude visa impedir a prescrição da sobrecarga de trabalho, deixando aos operários certa margem de manobra para configurarem seu tempo conforme seu próprio uso.

Vê-se, assim, que o operário detém certo controle da situação de trabalho, apesar de, comumente, seu trabalho ser concebido como estando aprisionado por normas rígidas, sejam as de segurança, de qualidade, de operação, sejam, mormente, aquelas referentes ao tempo necessário para cumprir cada operação, especialmente na linha de montagem, onde a importância do tempo é majorada.

Poder participar da condução e controle do tempo do trabalho fortalece o trabalhador e, sobremaneira, a categoria à qual pertence, como alude Inácio: ele "ganha corpo" à medida que consegue desenvolver aquela "técnica esperta". Para esse operário, "ganhar corpo" significa evitar a perda do trabalhador e não "apertar" o tempo de quem ficou na fábrica, o que só é possível por intermédio de certa "malícia".

Assim, os operários controlam a sobrecarga de trabalho manipulando o próprio corpo, cuidando do avanço da máquina e da gestão de riscos, buscando o maior equilíbrio possível entre a intensidade de trabalho, a produção, a segurança e o "tempo livre".

Por trás desses espaços de autoproteção que são criados pelos operários, ciosos dessa relativa liberdade, esconde-se o que Durand (1990) chama de jogo: "Atenuar a fadiga física e nervosa ocasionada pelo trabalho, jogando [...] Reinventar a cada instante. Permanecer criativo. Não se dobrar ao ritmo da máquina. Manter sua personalidade [...] Dizer não à rotina [...]" (p. 90).

\section{Batalha entre o corpo e os valores no trabalho}

A postura criativa e astuta do trabalhador está intrinsecamente vinculada a sua reformulação das normas do meio social em que vive. Segundo Canguilhem (2006, p. 86, p. 175), essa reformulação é inerente ao ser vivo; todavia, é também preciso considerar as circunstâncias nas quais o indivíduo é tolhido da capacidade de renormalizar.

No ambiente de trabalho, a saúde ganha um significado diferenciado daquele da lógica médica, da ausência de doença. Tendo como esteio a perspectiva de Canguilhem, Clot deixa claro que, quando os fatos ocorrem independentemente dos sujeitos que os vivem, estes são despojados de sua obra (2005, p. 11). Anuncia-se, assim, a: "'anemia' ordinária do trabalho, que mina a saúde de muitos assalariados e os expõem tanto à doença do corpo quanto à do espírito. Pois, o homem não pode, sem danos profundos, somente viver em um contexto. Ele tem de poder criar um contexto para viver" (Clot, 2005). 
Circunstâncias adversas estão presentes em certas situações de trabalho fabril, comumente acarretando doença e invalidez para o corpo do trabalhador. Sua exposição a substâncias tóxicas, cujos efeitos colaterais às vezes são pouco conhecidos ou, pelo menos, não divulgados dentro da fábrica, evidencia a sombria realidade à qual muitos operários estão expostos.

A operadora de dinamômetro, Ana, 22 anos, trabalha no teste de motores e está constantemente exposta aos danos provocados por uma substância chamada etilenoglicol. Trata-se de um produto químico largamente empregado pelas indústrias, cujos efeitos colaterais são extremamente danosos à saúde humana e que, porém, continua sendo usado sem precauções adequadas, pondo em risco a saúde e a vida daqueles que o manipulam.

O etilenoglicol é um fluido muito tóxico que, se ingerido, é venenoso. Basicamente, seus sintomas de envenenamento são semelhantes à intoxicação por álcool: ele atinge o sistema nervoso central, provocando o aumento de acidez e o desenvolvimento de cristais no sangue. Dependendo da quantidade ingerida e do tempo de exposição a essa substância "podem ocorrer falência renal, insuficiência cardíaca congestiva, lesão cardíaca e morte" ${ }^{\text {. }}$.

Inconformada com os efeitos lesivos causados pelo etilenoglicol, Ana considera que, embora no caso dos motores, a substância esteja diluída, o que teoricamente ameniza seus efeitos, como a exposição dos operários é diária, passa a haver intoxicação cumulativa.

Assustados com as consequências do fluido constatadas na internet, algumas das quais já percebidas em seus corpos, seja com o doce que deixa na boca, o amarelo nas mãos, as disfunções renais, seja com a ameaça à fertilidade feminina, os operários procuram os chefes e responsáveis pela segurança do trabalho para providenciarem uma solução a respeito. Apesar da constituição de uma engenharia química para estudar o caso, alcançada pela pressão dos operários, nenhuma medida severa havia sido tomada pela fábrica até então, muito embora o mercado disponibilize um produto similar e não nocivo à saúde (o propilenoglicol ${ }^{17}$ ).

A dramaticidade da situação traça um quadro sombrio em que os operários vivem a iminência de um desastre. Mesmo não se resignando e pressionando os responsáveis, eles têm de permanecer à espera de uma solução que, pelo menos em curto prazo, independe deles. Até que ocorra uma providência externa, estão reféns de sua própria sorte, impotentes diante da situação que não podem renormalizar.

Perfilado desse mesmo gênero de drama, está o sofrimento psicofísico dos operários atormentados por suas condições ergonômicas de trabalho. Dentre os operários entrevistados no trabalho de campo, o caso mais ilustrativo, dado o fato de sua experiência ser carregada de dor e humilhação, é aquele vivido por Jussara.

Na flor da idade, aos 27 anos, Jussara foi vitimada por doença de trabalho em uma grande montadora, dadas as condições precárias às quais teve de se submeter na linha de montagem de motores. Ela ingressou lá com 22 anos de idade, trabalhando diariamente sem talha para erguer peças muito pesadas. Cinco anos depois descobriu que já havia contraído uma doença profissional.

Clinicamente, a patologia que a acometeu é considerada grave e de difícil intervenção cirúrgica. Ela relata a sua situação, mencionando as insuportáveis dores que sente nas partes em que o seu corpo foi arruinado pelas condições rudimentares do seu trabalho.

Uma vez constatada a patologia, teve início um processo de perícia burocrático e moroso, corroborado por diagnóstico médico comprometido com as divisas da fábrica.

16 Conferir a enciclopédia do site: http://www.agendasaude.com.br.

17 Conferir http://www.inmetro.gov.br/consumidor/produtos/aditivos.asp. 
Somente depois de dois anos, a fábrica assumiu oficialmente sua responsabilidade sobre a doença da operária. Durante esse longo período de espera, seu quadro clínico agravou-se e tornou-se crônico.

Parcialmente invalidada pela doença do trabalho, Jussara teve seu título de trabalhadora alterado juridicamente para "compatível", o que consiste, em tese, na restrição de desempenho de certas tarefas cujos movimentos ultrapassam suas limitações físicas, como, por exemplo, trabalhar com os braços abaixo do ombro.

Não obstante essas restrições, a realidade dos deveres a ela atribuídos dentro da fábrica é bem diversa dos direitos assegurados em lei. Solicitada por seu chefe, indiferente ao seu estado, Jussara acaba preenchendo funções de postos vacantes, cujas tarefas lhe exigem exercer movimentos que lhe estão proibidos. Nem mesmo o rodízio de tarefas sana esse problema, uma vez que a maioria das trabalhadoras do seu setor já foi atingida por doença do trabalho.

O atributo do rótulo de "compatível" revela-se tão somente como uma máscara utilizada pela fábrica para ludibriar o controle de certificação de qualidade. Pois, a despeito da legislação trabalhista, efetivamente, as circunstâncias fabris obrigam os operários a trabalhar sem quaisquer restrições de tarefas.

Atrelado ao título de compatível vem o pejorativo de "vagabundo". Assim, surge um segundo gênero de sofrimento, não mais afetando o corpo físico, mas atingindo diretamente a psique do operário. Em situações como essa é corrente o trabalhador descuidar de sua saúde física, exercendo tarefas que lhe estão interditadas, para zelar por sua saúde psicossocial, prezando seu título de trabalhador. Portanto, a autodefesa do corpo se ausenta aqui para fortalecer a afirmação dos valores culturais do trabalhador.

De vítima do trabalho o operário passa a delinquente, cujo delito consiste em não querer trabalhar, portanto, descumprindo o contrato de trabalho assumido junto à fábrica. Porém, nessa atitude esconde-se um álibi: a ideologia fabril que mascara sua culpa. Segundo Carvalho (1989): "A doença é vergonhosa, sobretudo porque ela se manifesta pelos sinais do corpo [...] o trabalhador doente [...] é a denúncia constante do sistema opressor e imoral. Se ele é categorizado como 'delinquente', a chefia e o sistema estão 'a salvo' do julgamento, a opressão fica 'escondida'" (p. 147).

Um trabalhador doente fisicamente vive situação ainda pior em seus valores, como o orgulho: impossibilitado de trabalhar bem, ele desafia sua saúde para desempenhar como se estivesse em plena condição. Tudo isso para assegurar um trabalho "bem feito" e evitar ser chamado de ocioso.

Deflagra-se aí uma árdua batalha de valores, em que diversas vezes o valor "saúde" perde espaço para o valor "orgulho". O corpo do operário acaba se submetendo ao valor "orgulho" de ser trabalhador para impedir a desonra do viver coletivo fabril.

Aventando a discussão do "cuidado de si", Carvalho (1989) tece comentário acerca dessa ambiguidade de valores saúde-doença no trabalho. Conforme a autora, quando se entrega à doença originada no trabalho, o trabalhador o faz porque essa foi a única maneira que encontrou para "cuidar de si, cuidando de sua doença" (p. 158).

É inevitável passar pela perspectiva foucaultiana ao tratar do "cuidado de si". Conhecido como aquele que anunciou a "morte do sujeito" ao vinculá-lo à docilização dos corpos pelo poder disciplinar das instituições, no final da vida, Foucault dedicou-se à hermenêutica de si. $\mathrm{O}$ autor transitou da prática coercitiva para a prática da constituição de si do sujeito, fazendo emergir a importância do "cuidado de si", efetivado como prática de liberdade. Esse "cuidado de si" consiste no trabalho de si sobre si mesmo para elaborar um 
modo de ser. Embora esse modo de ser seja alcançado pela prática da liberdade, esta se encontra ontologicamente assentada na ética, ou ainda em valores coletivos (Foucault, 1994, p. 709). O autor argumenta que as práticas de si realizadas pelo indivíduo são ativas e inventadas, não por ele mesmo; elas consistem em "esquemas que ele encontra em sua cultura e que lhe são propostos, sugeridos, impostos [...]" (p. 719).

Tendo a sociedade grega clássica como referência, Foucault (1994) aduz ainda que "o cuidado de si" coincide com o cuidado do outro, porém o cuidado de si tem primazia ética, uma vez que a relação consigo mesmo tem prioridade ontológica (p. 715). Não obstante, vivendo em uma sociedade extremamente complexa, na qual valores e subjetividades se entrelaçam e se desacordam, no caso de Jussara, o que se verifica é inversão ontológica desse cuidado.

Com a vida cercada por restrições, tanto de ordem profissional quanto familiar, essa operária também teve de renunciar a importantes práticas que ajudam a selar os laços maternais, como dar colo a suas filhas. Certamente, a patologia laboral limitou sua vida privada e pública; no entanto, ela não aceita o título de inválida, e por isso pratica exercícios físicos, readequou seu espaço doméstico, re-normalizou sua relação com as filhas, estabeleceu, na medida do possível, trocas de tarefas em seu trabalho fabril, enfim, reinventou sua vida por completo para poder continuar.

Essa história de vida deixa uma grande lição ao enunciar que mesmo sendo complicado é preciso que cada um aprenda a lidar com o seu problema. Incentiva, portanto, a lutar com e pela vida. ${ }^{18}$

Compor a sua própria história, apesar das adversidades às quais se é submetido, carregar consigo o mérito de construir um mundo cotidiano, em que seja possível para alguém intervir no meio para torná-lo o mais condizente possível aos seus limites e aos seus valores. Eis o sentido das trajetórias de vida que se pôde apreender dos testemunhos dos operários aqui apresentados, trajetórias que revelam situações de júbilo, de sofrimento, de aprendizagem, de criatividade, de desventura, enfim, dramas. Dramas dos quais eles fazem "usos" ${ }^{19}$ mediante escolhas possíveis, tanto operacionais quanto valorativas advindas de si e dos outros. Assim, eles constituem seu meio ao mesmo tempo em que constituem a si mesmos, reinventando seu trabalho e seu próprio corpo físico, psíquico e social.

\section{Deixar a própria marca nos objetos produzidos}

A comunicação é uma das formas utilizadas pelos seres humanos para se assumirem como sujeitos pelo alcance de sua visibilidade, não necessariamente do seu corpo, mas utilizando-o como meio de transmissão de suas escolhas, histórias e valores.

Não é incomum encontrar operários, mesmo de grandes fábricas, que fazem esforço para deixarem sua marca sobre os objetos que fabricam. Com grande talento poético, Certeau (2004) descreve as práticas criativas dos trabalhadores que, aproveitando as sobras da fábrica, fazem artes para si: "com suas máquinas e graças aos seus resíduos, pode-se desviar o tempo devido à instituição; fabricar os objetos textuais que significam uma arte e solidariedades [...]

18 Essa mensagem recorda muito a lida no campo, belissimamente retratada nas canções Sina de violeiro e Tocando em frente, de dois admiráveis cantores e compositores-poetas brasileiros, o violonista Renato Teixeira e o violeiro Almir Sater.

19 A expressão "usos” está empregada aqui em oposição a "execução”, difundida pelo taylorismo, que concebe o operário como mero reprodutor de instruções previamente definidas por outro. Schwartz distingue as noções de "usos de si por si mesmo" e "usos de si pelos outros" intrinsecamente ligadas ao que ele denomina de "corpo-si", constituído pela relação entre o ser biológico, cultural e psíquico ou, ainda, pelo corpo, valores e escolhas dos indivíduos (2003, pp. 191-193, p. 197). 
inventar os traçados de conivências e gestos". Mesmo sofrendo as mazelas do trabalho, pode-se, assim, "subverter [...] a lei que, na fábrica científica, coloca o trabalho a serviço da máquina e, na mesma lógica, aniquila progressivamente a exigência de criar" (p. 90).

Ao confirmar a sua identificação com o seu modo de trabalhar, Pablo demonstra que aquela não reside somente em elementos abstratos e invisíveis, como o controle do tempo, o ritmo do movimento, a sequência de montagem, e também não se refere à criação de mecanismos, como engenhocas e dispositivos. Não se trata de elemento funcional visando diretamente à produção.

Trabalhando na pré-montagem de câmbio de caminhão, para estabelecer identificação com a sua atividade, ele fazia inscrições de trechos de poesias e de orações no interior do câmbio, porém escrevia sem dar espaço entre as palavras. Quando o câmbio chegava na linha de montagem, seus colegas tentavam adivinhar as mensagens; assim, eles estabeleciam um jogo de interação cujo intuito parecia ser o de "descoisificar" as suas relações; ou seja, desconstruindo o conceito marxiano de "fetiche da mercadoria" ${ }^{20}$, nessa situação os operários não se relacionam com as coisas, mas com os outros operários por meio das coisas.

Essa forma de identificação de Pablo com seu trabalho é gestada da necessidade que o ser humano tem de se diferenciar das coisas, mas por intermédio das coisas; da necessidade de se afirmar como um animal, sim, porém, emocional. Essa necessidade pertence ao mundo sensível da arte.

Escrever versos e frases bíblicas no interior do câmbio foi uma forma encontrada por esse operário para se expressar, reafirmando sua subjetividade e negando o papel de simples reprodutor de objetos-massa. A inscrição de frases nas peças torna-as singulares, não por um capricho dele em relação ao objeto, mas em relação a si próprio. Com esse ato, o operário busca revelar o que é. Por pequena que seja, a singularização que as escolhas de frases possibilitam e representam alcança a posteridade, transportada na peça que os caminhões carregarão continente afora.

Arendt considera a poesia como a arte mais humana e menos mundana, que detém sua durabilidade por meio da linguagem e sua recordação pela memória viva. Todavia, embora sendo pouco mundana, para perdurar ela precisa ser escrita, tornar-se tangível em coisas para não perecer (Arendt, 1987, p. 183). É nesse prisma que Pablo registra seus versos em linguagem escrita, não para essa arte em si perdurar, mas para ele mesmo perdurar por meio dela.

Os critérios aos quais ele recorre para escolher as sentenças que registra nos câmbios demonstram algo curioso: suas frases de cunho religioso questionam sua postura ateia. Diante da contradição, o jovem operário reage de súbito desapontado e inconformado com a observação: "Não, não! Não é isso! É só uma frase assim, tipo: tem frase que eu acho bonita, não que eu acredite tal! Mas tem frase que eu acho legal, acho bonita. Aí eu colocava".

Ele justifica a escolha das frases pelo critério da estética, e não da ideologia; não são sentenças nas quais ele acredita, mas frases que admira pela beleza, o encadeamento das palavras, quaisquer que sejam os sentidos portados por elas.

Deriva daí um valor diferenciado conferido à escrita, sua importância desvinculada da mensagem em si; no caso a primazia é dada ao papel de comunicadora de feitos entre seres humanos. Comunicar não o sentido do que é escrito, mas o sentido que o ato da escrita pode deixar manifesto, fazendo com que o leitor pense a esse respeito.

20 Para Marx (1983), “os produtos do cérebro humano parecem dotados de vida própria, figuras autônomas que mantêm relações entre si e com os homens” (p. 71). O que efetivamente se verifica nas sociedades capitalistas, porém, há situações em que ocorre o contrário, inclusive entre os operários, concebidos como uma categoria de alienados. 
Ver os caminhões transitarem pelas ruas e imaginá-los sua obra, sobretudo marcados por frases que brotaram de suas mãos e de sua escolha, leva Pablo a um estado de êxtase. Ele afirma com orgulho que cada câmbio "tem sua marca registrada". Quando um caminhão passa por ele, pensa: "será que eu escrevi nesse? Eu fico imaginando [...] um dia parar na oficina e [...] pegar o câmbio [com] frases e escrito o meu nome. Nossa! Eu montei, realmente!" Portanto, o objeto em si não é testemunho de sua ação em produzi-lo, precisa de uma marca sua para tornar tal ação crível.

Fisher (1980) nota que atividades desse gênero, como marcar, construir fronteiras ou colecionar objetos na fábrica, deixam traços de cada um e criam pontos de referência no espaço, de tal modo que, por meio delas, o "espaço se inscreve na personalidade do indivíduo como um laço de identidade" (p. 181). Marcar objetos de sua produção é um meio de afirmação de si, pois o objeto marcado por seu criador expressa o vínculo afetivo entre o sujeito e a sua obra.

O operário marca os objetos que fabrica como se eles fossem uma obra de arte, e, de certo modo, sente-os dessa forma, pois deposita neles suas qualidades de autor singular, uma vez que ninguém trabalha igual a outrem. Assim, ele "ganha um espaço, assina aí sua existência de autor" (Certeau, 2004, p. 94).

Destacando a impossibilidade de os métodos oficiais apreenderem e reproduzirem a precisão e a variabilidade dos gestos astutos dos operários, de forma lapidar, um operário, apresentado por Oddone, Re e Briante (1981), sublinha: "mesmo que o patrão, observando os gestos do operário e a harmonia de seus movimentos, roube certa quantidade de suas astúcias, será impossível esgotá-las inteiramente" (p. 65).

O caráter singular do trabalho também foi mencionado por Alex referindo-se à atividade de pintura interna de carro. Ele a classifica como um trabalho artesanal, que cada operário realiza de forma particular e inimitável. Em sua ênfase para a singularidade dessa atividade ele reporta a impossibilidade de documentar sua operacionalização.

O jeito do pintor está gravado na textura do carro que pinta, pintura tão singular que traz a assinatura do seu artista. Certamente, pode-se interpretar a necessidade da assinatura do pintor como um controle feito pela fábrica, para saber exatamente quem cometeu eventuais falhas. ${ }^{21}$ Porém, isso não retira da assinatura sua áurea artística, pois evidencia a inexequibilidade estética de um pintor conseguir reparar uma incorreção cometida por outro.

Para Canguilhem a transição da condição de indivíduo para a de sujeito se dá quando aquele produz na sociedade "novas possibilidades que interrogam a individualidade inicial", ou seja, aquela determinada pelos outros. Ele concebe a normatividade como inventiva, facultando a "variedade de normas individuais", que "permite a cada um se constituir como sujeito de seu meio". Conclui ainda que a "reflexibilidade do sujeito na atividade produtiva constitui uma autêntica relação consigo mesmo" (apud Le Blanc, 1998, pp. 98-100).

Cotejando as marcas pessoais superpostas aos objetos pelos operários com essa acepção de Canguilhem, tem-se que os objetos que adquirimos não carregam somente matéria morta; eles portam vestígios de gente que, trabalhando, gere coisas e se gesta pelas coisas. Alex fornece uma frase primorosa a esse respeito, enunciando que fábrica e cliente, quando adquirem os objetos produzidos pelo operário: "vai ter o funcionário agregado ao carro e não só a marca do carro".

Portanto, essa característica de singularidades impressas nos objetos produzidos na fábrica a sugere como um lugar bastante distanciado daquele de pura reprodução em massa de produtos, feitos por ações mecanicistas de operadores.

21 Conferir Oddone, Re e Briante (1981, p. 135). 


\section{Conclusão}

Longe de serem compostas por sentidos concernentes à alienação, certas práticas operárias dentro das fábricas são do tipo tático, pois evidenciam atitudes ardilosas, cujo intuito corrobora não somente os interesses produtivistas da fábrica, mas também os do corpo e dos valores dos operários.

Tais práticas foram apresentadas neste artigo a partir de quatro diferentes eixos temáticos, a saber: a) produção e corpo, b) intensificação do trabalho, c) corpo e valores, e d) personalização de objetos.

$\mathrm{Na}$ temática produção e corpo, percebe-se que os operários desenvolvem formas astuciosas para controlar a produção a partir do ritmo do seu próprio corpo, criticando, em ato, a mera adequação taylorista do corpo à máquina.

Tendo em vista que o tempo consiste no principal desafio do trabalho fabril, o operário constrói formas de fazer com que o ritmo da produção se conforme com a pulsão do seu corpo. Esse tipo de controle do operário deixa estampado que a produção não detém em absoluto o domínio sobre o seu corpo, já que ele consegue fazer uso do tempo fabril de modo a impedir, na medida do possível, que seus limites pessoais sejam ultrapassados.

Concretamente, essa astúcia de controlar o ritmo da produção por meio do tempo subjetivo do operário ocorre pela antecipação da produção, acarretando períodos vazios entre as etapas de trabalho, por sua vez utilizados conforme suas necessidades físicas e subjetivas. Uma das formas específicas de facultar esse adiantamento da produção é realizada pela técnica da "bolsinha", que reduz significativamente os deslocamentos durante a jornada de trabalho; logo, ameniza, em grande medida, o cansaço causado pelas constantes buscas de suprimentos.

O segundo tipo de prática empregada pelo operário se refere à elaboração de estratégia contra a intensificação do trabalho. Trata-se do chamado "espaço manhoso", forma com que é nomeado pelo vocabulário nativo dos operários, uma prática ardilosa assumida por eles para evitar que a cronometragem do engenheiro diminua seu tempo de trabalho em cada tarefa.

"Espaço manhoso" consiste em um intraespaço fabril elaborado pelo operário para evitar o seu subjugo total pelas normas coercitivas do trabalho. Esse novo espaço é gestado por tempos e movimentos corporais diferentes daqueles impostos pelas normas oficiais e mais condizentes com as escolhas dos operários, minimizando esforços e intensidade de trabalho. Por intermédio de tais movimentos controlados, os operários fazem uso de técnicas de avanço ou retardo do ritmo das máquinas ou do seu corpo.

Ao recorrer a esse "espaço manhoso", os operários gerenciam tanto a produção quanto os riscos, propiciando, portanto, a segurança no trabalho e condicionando o usufruto do "tempo livre", por sua vez utilizado conforme suas necessidades psicofísicas e valorativas, ou seja, desde o descanso até o cultivo de amizades e realização de leitura.

A terceira prática operária diz respeito à díade corpo-valores, recoberta por ambiguidade e conflitos impingidos pelos limites existentes entre o corpo e os valores simbólicos dos operários.

Muito embora os seres humanos disponham da habilidade de autodefesa perante ameaças de toda espécie, há ocasiões em que são premidos à doença, situação um tanto recorrente no ambiente fabril, no qual os operários estão à mercê de más condições de trabalho. Quando são atingidos por elas, adquirindo doenças do trabalho, são considerados "compatíveis", termo que teoricamente os restringe à realização de certas tarefas; entretanto, 
ao fazerem valer seus direitos, são intitulados "vagabundos", o que os afeta a psique e denuncia um sistema capitalista absolutamente opressor.

Para se eximir do título de "vagabundo", comumente, o operário deixa de fazer valer seus direitos e assume tarefas que lhe são interditadas, revelando, assim, uma batalha acirrada entre os valores "saúde" e "orgulho". Essa situação contraria a máxima grega do período clássico antigo, analisada por Foucault (1994, p. 715), em que o "cuidado de si" tinha primazia sobre o cuidado do outro. Em contrapartida, no caso de alguns operários aqui pesquisados, eles desafiam sua saúde, sendo o cuidado do outro manifesto na coletividade do trabalho, primado em detrimento da defesa de si. Donde a ambiguidade dessa prática, que preza apenas pelos valores culturais.

Todavia, não obstante esse descuido de si, imposto pela ideologia do trabalho sobre o operário, percebe-se em diversas circunstâncias formas de recuperação dos sentidos de si, de sua subjetividade por parte do operário (Clot, 1992, p. 59). Essa gestão singular de si, cujo empenho constante busca favorecer o meio aos seus valores, transforma o indivíduo-massa em sujeito criador de sua micro-história.

A gestão singular de si ficou patente na última prática operária, que trata da personalização dos objetos fabricados, objetos sobre os quais o operário faz questão de deixar sua própria marca de sujeito. Objetos, portanto, que aparentemente são vistos como objetosmassa, mas que são ressignificados pela impressão pessoal do operário, que, na prática, nega ser avaliado como alienado e amorfo.

A inscrição de frases no interior da peça que fabricava, estabelecendo uma rede de relações entre os operários, mostra que o montador Pablo não visa uma simples brincadeira para provocar a decifração de palavras, mas expõe marcas de seres racionais e emotivos que precisam de visibilidade e de singularidade, por trás das peças aparentemente idênticas. Os sinais registrados no câmbio vêm testemunhar seu trabalho, parecem necessários para fazê-lo acreditar que ele mesmo o produziu. É a prova inquestionável do orgulho que sente em deixar parte de sua singularidade marcada no campo do visível.

O processo de atribuição de características subjetivas do operário aos objetos que fabrica acarreta realidade gestada por trabalhador-sujeito, e não por trabalhador-massa. Donde é revelada a assunção de sua condição de sujeitos pelos operários. Sujeitos que, por meio de ações táticas, mostram que um objeto não é constituído somente por matéria-prima e operações padronizadas, mas também indica a presença de gente, de jeitos próprios de trabalhar, de renormalização, de escolhas, de usos, de dramas, de valores.

\section{Referências}

Arendt, H. (1987). A condição humana. Rio de Janeiro: Forense Universitária.

Athayde, M. \& Brito, J. (2003). Trabalho, educação e saúde: o ponto de vista enigmático da atividade. Revista Educação, Saúde e Trabalho, 1 (2), 63-89.

Bernoux, P. (1979). De la résistance ouvrière à la rationalisation: la réappropriation du travail. Sociologie du travail, 1 (especial), 76-90.

Both, E. (1976). Família e rede social: papéis, normas e relacionamentos externos em famílias urbanas comuns. Rio de Janeiro: Francisco Alves.

Bourdieu, P. (1987). A miséria do mundo. Petrópolis: Vozes.

Canguilhem, G. (2006). O normal e o patológico (6ª ed. Rev.). Rio de Janeiro: Forense Universitária. 
Carvalho, M. C. R. G. (1989). O trabalho e a sombra: investigação de aspectos perceptivos e simbólicos do trabalho com máquinas na linha de montagem. Tese de Doutorado, Instituto de Psicologia, Universidade de São Paulo, São Paulo.

Certeau, M. (1994). A invenção do cotidiano: artes de fazer. Rio de Janeiro: Vozes.

Chaui, M. (1997). Comentários. Revista Subjetividades Contemporâneas, 1 (1), 18-25.

Clot, Y. (1992). La vigilance peut-elle être automatisé? Performancences Humaines $\mathcal{E}$ Techniques, fora de série, 56-59.

Clot, Y. (2005). Re-créer le travail. Les Cahiers de l'IFOREP, 113, 10-13.

Clot, Y., Rochex, J. Y. \& Schwartz, Y. (1990). Caprices des flux: les mutations technologiques du point de vue de ceux qui les vivent. Vigneux: Matrice.

Dejours, C. (2004). Inteligência prática e sabedoria prática: duas dimensões desconhecidas do trabalho. In S. Lancman \& L. I. Sznelwar (Orgs.), Christophe Dejours: da psicopatologia à psicodinâmica do trabalho (pp. 277 299). Rio de Janeiro: Fiocruz.

Durand, M. (1990). Grain de sable sous le capot. Montreil, France: La Breche-PEC.

Giddens, A. (1994). Modernidade e identidade pessoal. Oeiras, Portugal: Celta.

Fischer, G. N. (1980). Espace industriel et liberté: l'autogestion clandestine. Paris: PUF.

Foucault, M. (1994). L'éthique du souci de soi comme pratique de la liberte. In Dits et écrits (pp. 708-729, vol. 4). Paris: Gallimard.

Johnson, A. G. (1997). Dicionário de sociologia: guia prático de linguagem sociológica. Rio de Janeiro: Zahar.

Le Blanc, G. (1998). Canguilhem et les normes. Paris: PUF.

Marx, K. (1983). O capital: crítica da economia política. São Paulo: Abril.

Montmolin, M. (1986). L'intelligence de la tâche: eléments d'ergonomie cognitive (2aㅡ. ed.). Berne: Peter Lange.

Oddone, I., Re, A. \& Briante, G. (1981). Redécouvrir l'expérience ouvrière: vers une autre psychologie du travail? Paris: Messidor.

Rosa, M. I. (2000). Trabalho - nova modalidade de uso de si e educação: debates/confrontos de valores. ProPosições, 11 (2), 51-60.

Rosa, M. I. (2005). Usos de si e densificação do trabalho. In: Dieese (Org.), Trabalho e abordagem pluridisciplinar: estudos Brasil, França e Argentina (pp. 17-33). São Paulo: Dieese.

Sato, L. (1997). Astúcia e ambigüidade: as condições simbólicas para o replanejamento negociado do trabalho no chão de fábrica. Tese de Doutorado, Instituto de Psicologia, Universidade de São Paulo, São Paulo.

Schutz, A. (1979). Fenomenologia e relações sociais. Rio de Janeiro: Zahar.

Schwartz, Y. (1988). Expérience et connaissance du travail. Messidor: Éditions Sociales.

Schwartz, Y. (1992). Travail et philosophie: convocations mutuelles. Toulouse: Octarès.

Schwartz, Y. (2000). Le paradigme ergologique ou un métier de Philosophe. Toulouse: Octarès.

Schwartz, Y. (2003). Travail et ergologie: entretiens sur l'activité humaine. Toulouse: Octarès.

Thiollent, M. (1982). Crítica metodológica, investigação social e enquete operária (3⿳ㅗㄹ. ed.). São Paulo: Polis.

Vernant, J. P. (2003). O universo, os deuses, os homens. São Paulo: Cia. das Letras.

\section{Endereço para correspondência}

cris@fafcs.ufu.br 